\title{
A Universal Code of Ethics for Professional Accountants: Religious Restrictions
}

\author{
Marcela Espinosa-Pike, Itsaso Barrainkua \\ University of the Basque Country UPV/EHU, Bilbao, Spain
}

\begin{abstract}
The International Federation of Accountants (IFAC) has emerged as a worldwide organization to help bring about international convergence with regard to professional standards, including standards governing ethics. The IFAC has issued a Code of Ethics for Professional Accountants for use by accountants members of the IFAC around the world. This study extends prior research about the variables that could block the possibility of adopting the universal single code of ethics proposed by the IFAC. In particular, this study analyses the influence of the dominant religious affiliation of the country to which the accounting organization belongs on the decision to adopt the IFAC Code. Data about 165 accounting bodies, members of IFAC, from 125 countries has been obtained from the IFAC Member Body Compliance Program. The results of our study show that to date, not all the accounting organizations members of the IFAC have adopted the Code. Further, results reveal that religion is a significant factor in the decision to adopt IFAC Code of Ethics. In particular, the study demonstrates that the national accounting organizations belonging to countries where the predominant religion is Christianity are more prone to adopt the IFAC Code of Ethics as their own. This paper contributes to the knowledge of the current state of ethical harmonization for the accounting profession. Moreover, an understanding of the religious restrictions provides guidelines to the international accounting organizations for an effective implementation of the ethical standards worldwide.
\end{abstract}

Keywords: accounting profession, code of ethics, religion, International Federation of Accountants (IFAC)

\section{Introduction}

As businesses have developed globally and multinational companies have tended to dominate the economy, the importance of strengthening the confidence in the accounting profession worldwide is essential. In this respect, the internationalization and harmonization of the accounting profession and its study have gained increased interest in the last decades. The internationalization of the accounting profession requires convergence both in terms of the technical aspects of the profession and in training and ethical aspects. In this regard, the process of harmonization also focuses its attention on achieving consensus regarding certain common standards of conduct for the professionals. Therefore, in the current global market environment, international codes of ethics are receiving considerable attention among researches.

Marcela Espinosa-Pike, Ph.D., Senior Lecturer, Faculty of Economics and Business, University of the Basque Country UPV/EHU.

Itsaso Barrainkua, Ph.D. Candidate, Faculty of Economics and Business, University of the Basque Country UPV/EHU.

Correspondence concerning this article should be addressed to Marcela Espinosa-Pike, Avda. Lehendakari Agirre 83, 48200 Bilbao, Spain. E-mail: marcela.espinosa@ehu.es. 
Codes of ethics are a distinguish mark of a profession. Society grants professions a high social status, autonomy, and power to regulate the activity. In return for the privileges granted, society has the legitimacy to demand that professionals perform their work in a responsible manner (Sheldahl, 1980).

The IFAC has emerged as a worldwide organization to help bring about international convergence with regard to professional standards, including standards governing ethics (IFAC, 2013). The IFAC, which is an organization comprising 167 members and associates in 127 countries, issued the Code of Ethics for Professional Accountants. A member of the IFAC shall not apply less stringent ethical standards than those stated in the Code. This universal code provides a framework for common action to be taken with a view to guiding professionals in dealing with the conflicts of interest in which they may become embroiled. In this regard, the Code of Ethics issued by the IFAC, is structured around the establishment of the moral obligations or responsibilities of its members along general lines, so as then to develop in more or less detailed form the specific rules of conduct deriving from previous responsibilities or principles.

However, it should be taken into account that professional conduct, values, and ethical standards depend on the values and ethical standards of the society in which professionals operate and therefore, these values are highly influenced by cultural, religious, and socioeconomic aspects that make the universality of ethical principles difficult to achieve (Cohen, Pant, \& Sharp, 1992).

Religion is one of the strongest influences in individual's behavior. In this respect, religious beliefs could be compiled in some sense in this Code of Ethics. Codes of ethics are an important expression of societal values shared by individuals pertaining to the same society, in addition, religions offer particular ethical values to society. Therefore, the barriers for the harmonization of ethical codes of conduct could appear from the differences between the moral and ethical values reflected in the codes and the religious values shared by individuals.

To date, not all the countries that belong to the IFAC, have adopted the code proposed by the IFAC, nor have the countries that have adopted it done so in the same way (Clements, Neill, \& Stovall, 2009). The question being raised is whether it is possible to have a universal code of ethics for accountants worldwide which does not contravene the values and standards that are commonly accepted and shared by the countries in which it operates. In this regard, what is on debate is if this Code could be useful for all the countries considering that they have significant different religions. In particular, this study deals with the effect of religions on the adoption of the IFAC Code of Ethics by professional bodies around the world. To this end, a study has been carried out on the decision taken by professional organizations from the countries members of the IFAC. The purpose of this paper is to examine whether the religious differences could restrict the adoption of a universal a code of ethics for the accounting profession worldwide. This paper contributes to the knowledge of the current state of ethical harmonization for the accounting profession. Moreover, an understanding of the religious restrictions provides guidelines to the international accounting organizations for an effective implementation of the standards of conduct worldwide.

The work is divided into the following sections. Following the introduction, a review is carried out of the academic literature regarding the influence of religion in the codes of ethics. In the third section, the methodology and data used to carry out the study are provided. In the fourth section the results regarding the influence of religion are presented and, lastly, the most relevant conclusions drawn and future lines of research are set forth. 


\section{Literature Review}

Academic literature has tried to establish the influence of religion in ethical outcomes. Religious ideology influences an individual's judgment of right and wrong (Rest, 1986). As Brammer, Williams, and Zinkin (2007, p. 229) pointed out, organized religion has sought to play a significant role in establishing and disseminating moral and ethical prescriptions that are consistent with religious doctrines and that offer practical guidance to those involved in business concerning ethical conduct.

Even though some western ethicist has neglected the religious tradition of business ethics (Calkins, 2000), a growing body of literature has attempted to address the influence of religion in business ethics (Epstein, 2002; Graafland, Kaptein, \& Schouten, 2006). Bartels (1967, p. 23) observed that some culture characteristics, such as religion, were some of the influences upon business decisions that lie outside the realm of purely economic motivation. Hunt and Vitell (1993) proposed a model for ethical decision making in which they included religion in among both the cultural environment and personal characteristics, which influenced the perceived problem, as well as its alternatives and consequences. According to this model, religiousness may influence the set of possible alternatives that an individual perceives to resolve the ethical problem.

Academic literature has addressed the effect of religion on business ethics through diverse streams. Particularly, in the field of accounting ethics, Keller, K. T. Smith, and M. S. Smith (2007) conducted a survey among US accounting students which revealed that religion was a strong foundation for ethical decision making. Following this research line, Ho (2009) found that accounting students in Taiwan with religious beliefs revealed higher levels of ethical reasoning abilities. However, religion can not only influence the ethical decision-making, but may also influence the expected behavior of individuals. In this sense, religion is a key element in defining codes of conduct. As Graafland et al. (2006, p. 55) suggested, people's expectations of others will be influenced by their religious beliefs.

The IFAC Code of Ethics for Professional Accountants has been developed and issued by the International Ethics Standards Board for Accountants (IESBA). IESBA is an independent standard-setting board supported by the IFAC. Although IESBA established ethical requirements for professional accountants worldwide, the board members (IFAC, 2012) are mostly experts from Anglo-Saxon countries and Western Europe. Besides, looking at the five members representing the Transnational Accounting Firms, practitioners belonging mostly to the Big four and Grant Thornton LLP, the predominance of the Anglo-Saxon tradition is noticeable. Therefore, the concern being raised is whether a small group of experts from Anglo-Saxon tradition can regulate the practice of more than 2.5 million professionals all over the world (Loft, Humphrey, \& Turley, 2006); taking into account the great diversity of culture, language, economic status and, in particular, religion differences.

In these western countries, the predominant religion is Christianity. Christianity is still the major religion in the West and serves as an ethical framework for many in their personal lives (Kim, Fisher, \& McClaman, 2009, p. 116). In common with McMahon (1986), Calkins (2000, p. 343) claimed that Christian, and in a lesser extent Jewish, precepts and narratives have shaped Western business ethics through their influence on law and culture. Accordingly, ethics standard setters might be affected by a Christian moral perspective and this, therefore, could be reflected in the Code. The Code of Ethics includes a set of values and principles that professional accountants should adhere to and those might be influenced by the religious foundation of the Code. 
The second-largest religion in the world is Islam. Lewis (2001) explained that the Islamic law, shari'a regulates all aspect of life. Therefore accountants must perform their duties in accordance with this and base their actions on Islamic ethical norms. According to IFAC, cultural and ethical diversity should be considered when evaluating whether the public interest is being served (IFAC, 2012a). In this sense, the extent to which religious customs shape legal and commercial systems must be taken into account. Muslim accountants must make sure public interest is in line with Islamic principles (Al-Aidaros, Idris \& Shamsudin, 2011). In this regard, Haniffa and Hudaib (2007) showed the dissatisfaction of the Saudi auditors with the "borrowed" codes that do not reflect the Islamic ethical values. According to these authors, the exclusion of the Islamic principles in the regulations and code is one of the main drivers for the expectation gap between auditors and users. Similarly, in a study conducted in Yemen, Al-Aidaros et al. (2011) concluded that the users of accounting information expected the professional accountants not only to behave according to American Institute of Certified Public Accountants (AICPA) or IFAC general principles but also to comply with the Islamic principles.

Religion is one of the most important factors that can affect an individual's behavior (Ho, 2009). Therefore, if there is any controversy between religious beliefs and the principles stated in the professional code of ethics, this controversy might cause a dilemma to the individual. As Graafland et al. (2006, p. 56) stated a dilemma generated by a conflict between a moral standard and a religious standard is classified as an existential religious dilemma. According to the study carried out by these authors, when individuals confront business dilemmas, religious standards often override moral standards.

The differences in the ethical systems, as well as the fact that religion rules all aspects of life in many countries, bring us to suggest that religion may influence the adoption of universal code of ethics worldwide. In other words, organizations in countries in which the main religion is not Christianity may have other values not aligned with the IFAC Code and therefore, may be more likely to develop their own code of ethics. On the contrary, societies in which their religion beliefs are in accordance with those stated in the IFAC Code of Ethics are likely to accept this Code. Therefore, our hypothesis states as follows:

H1: IFAC member national accounting organizations belonging to countries in which Christianity is the predominant religion are more likely to adopt the IFAC Code of Ethics.

\section{Data and Methodology}

The sample used is made up of 165 accounting bodies from 125 countries. Data about the national accounting organizations have been obtained from the IFAC website (IFAC, 2012). Each member and associate of IFAC must complete the questionnaires and plans of action attached to the IFAC Member Body Compliance Program. The questionnaire about the adoption of the IFAC Code was completed by accounting bodies from different countries in 2006 and 2007 and has been revised via plans of action that have been carried out during 2011 and 2012. In respect to the adoption of the code, professional bodies must choose one of the following options: (1) Our organization adopted the IFAC Code as issued without modifications; (2) Our organization adopted the IFAC Code but with modifications; (3) Our organization has not adopted the IFAC Code as its own, but is involved in a process aimed at bringing its code in line with that of the IFAC Code; and (4) Our organization develops our own ethical requirements and uses another approach to incorporate the IFAC Code. It is the member bodies themselves that provide the answers. One hundred and sixty-seven IFAC members and associates have provided self-assessment information. However, Cayman Islands and Kosovo are not included 
in the sample due to the impossibility to obtain information on these territories. According to Clements et al. (2009), the IFAC member bodies are classified into two categories. The first one encompasses those that have adopted the IFAC Code with or without modifications (options 1 and 2 of the questionnaire), and the second one covers those that have not adopted the code and develop their own ethical requirements (options 3 and 4 respectively). As regards to the dependent variables, data about a country's dominant religion have been compiled from a dataset created by The University of Sheffield, as a part of the Worldmapper project (Worldmapper, 2012).

\section{Results}

Table 1 shows the distribution of the national accounting organizations according to the religious affiliation of the countries to which they belong and whether these organizations have adopted the IFAC Code of Ethics or not.

Table1

Summary of Religious Affiliations and IFAC Code Adoption

\begin{tabular}{|c|c|c|c|c|c|c|}
\hline \multirow{3}{*}{ Religion } & \multirow{2}{*}{\multicolumn{2}{|c|}{ IFAC members by the religion of their country }} & \multicolumn{4}{|c|}{ IFAC Code } \\
\hline & & & \multicolumn{2}{|c|}{ Yes } & \multicolumn{2}{|l|}{ No } \\
\hline & $N$ & $\%$ & $N$ & $\%$ & $N$ & $\%$ \\
\hline Christianity & 111 & $67.27 \%$ & 70 & $63.06 \%$ & 41 & $36.94 \%$ \\
\hline Islam & 33 & $20.00 \%$ & 16 & $48.48 \%$ & 17 & $51.51 \%$ \\
\hline Buddhism & 7 & $4.24 \%$ & 3 & $42.86 \%$ & 4 & $57.14 \%$ \\
\hline Hinduism & 4 & $2.43 \%$ & 2 & $50.00 \%$ & 2 & $50.00 \%$ \\
\hline Judaism & 1 & $0.61 \%$ & 0 & $0.00 \%$ & 1 & $100.00 \%$ \\
\hline Other & 9 & $5.45 \%$ & 4 & $44.44 \%$ & 5 & $55.55 \%$ \\
\hline Total & 165 & $100.00 \%$ & 95 & $57.58 \%$ & 70 & $42.42 \%$ \\
\hline
\end{tabular}

As it can be seen in Table 1, from the total of the sample $(n=165), 95$ are the national accounting organizations that have adopted the IFAC Code of Ethics, which means that the $57.58 \%$ of the total, have adopted the code. A comparison of the code adopter organizations between different religions shows that the national accounting organizations belonging to countries in which Christianity is the major religion are the ones that adopt the IFAC Code in a larger percentage. While the $63.06 \%$ of the Christian countries adopt the IFAC Code; $48.48 \%$ of the Muslim countries which adopt it. With respect to the rest of religions, the $42.86 \%$ of the national accounting bodies in the Buddhist countries and the $50 \%$ in the Hindu countries have adopted the IFAC Code. In the case of other religious denominations, the $44.44 \%$ of the organizations have adopted the Code. Finally, Israel is the only country in which Jewish religion is predominant and the national accounting organization has not adopted the code.

In order to analyze the significance of Christianity in this decision, the organizations are divided into two groups. One group is comprised by the organizations belonging to Christian countries and the other is formed by the rest of the organizations, which are those organizations belonging to non-Christian countries. This second group is referred to as "others". A chi-square test was conducted to determine if Christianity is related to the accounting organizations' decision of adopting the IFAC Code of ethics. The categories for the national accounting bodies are adopters or non adopters according to the responses of the IFAC Member Body Compliance Program. Results of the bivariate chi-square test are reported in Table 2. 
Table 2

Chi-square Test for the Relationship Between IFAC Code Adoption and Religion

\begin{tabular}{lllll}
\hline Countries' predominant religion & & Adopt & Non-adopt & Total \\
\hline \multirow{2}{*}{ Christian } & $N$ & 70 & 41 & 111 \\
& $\%$ & $63.06 \%$ & $36.94 \%$ & $100 \%$ \\
Others & $N$ & 25 & 29 & 54 \\
& $\%$ & $46.29 \%$ & $53.70 \%$ & $100 \%$ \\
Total & $N$ & 95 & 70 & 165 \\
$\chi^{2}=4.18$ & $\%$ & $57.57 \%$ & $42.42 \%$ & $100 \%$ \\
$p=0.041$ & & & & \\
\hline
\end{tabular}

The results in Table 2 show that Christianity has a significant influence $(p<0.05)$ over the organizations' decision to adopt the IFAC Code of Ethics for Professional Accountants. This means, organizations belonging to countries in which the dominant religion is Christianity are more likely to adopt the IFAC Code of Ethics instead of drawing up their own code of ethics.

\section{Conclusions}

As markets have steadily developed worldwide, so has the internationalization of the accounting profession and reconciliation with regulations, including ethical standards, proved essential. The IFAC has issued a Code of Ethics for Professional Accountants, which is supposed to be acceptable and appropriate for all professionals from the different countries members of the IFAC. However, the acceptance and effectiveness of this universal code of ethics may be affected by different variables. The academic literature has not observed the influence of religion in the decision to adopt the IFAC Code or, conversely, to develop their own code of ethics.

To date, not all the countries members of the IFAC have adopted the Code proposed by the IFAC. From the total of the sample (165 national accounting organizations from 125 countries) nearly $60 \%$ have adopted the IFAC Code of Ethics. The results of our study confirm our hypothesis that IFAC member national accounting organizations belonging to countries in which Christianity is the predominant religion are more likely to adopt the IFAC Code of Ethics. This result could uphold the thesis that religious beliefs influence the Code of Ethics. In this sense, IFAC ethics standard setters might be affected by a Christian moral perspective and this, therefore, could be reflected in the Code.

Our work provides new evidence with regard to the restrictions that may prevent effective acceptance and implementation of a universal code of ethics for the accounting profession. It broadens the scope of research that has been previously carried out by introducing religion, and in particular, Christianity, as a new variable to take into account. The IFAC, in its intention to lead the global harmonization for professional accountant all over the world, and in particular, in its attempt to reach an agreement on an international code of ethics, should take into account this religion restriction.

It will be necessary to delve into the specific religious beliefs that affect the acceptance of this Code of Ethics. A possible line of research is to identify in the IFAC Code of Ethics, Christianity traits or proper values. Future research could also analyze the possible contradictions with other religion beliefs that may exist in the current Code of Ethics and that impede its acceptance by professional organizations of non-Christian countries.

One limitation of this study is that the data regarding the decision to adopt the Code have been gathered 
from questionnaires completed by the accounting bodies themselves. The criterion used when determining whether modifications have been introduced or their own code has been developed may vary greatly among different bodies. Similarly, the data have been updated by using the information available from plans of action and this may prove ambiguous on occasions.

\section{References}

Al-Aidaros, A., Idris, K. M., \& Shamsudin, F. M. (2011). The accountant's ethical code of conduct from an islamic perspective: Case in Yemen. Journal of Global Management, 2(1), 98-123.

Bartels, R. (1967). A model for ethics in marketing. Journal of Marketing, 31(1), 20-26.

Brammer, S., Williams, G., \& Zinkin, J. (2007). Religion and attitudes to corporate social responsibility in a large cross-country sample. Journal of Business Ethics, 71(3), 229-243.

Calkins, M. (2000). Recovering religion's prophetic voice for business ethics. Journal of Business Ethics, 23(4), 339-352.

Clements, C., Neill, J. D., \& Stovall, O. S. (2009). An analysis of international accounting codes of conduct. Journal of Business Ethics, 87, 173-183.

Cohen, J., Pant, L., \& Sharp, D. (1992). Cultural and socioeconomic constraints on international codes of ethics: Lessons from accounting. Journal of Business Ethics, 11(9), 687-700.

Epstein, E. M. (2002). Religion and business-The critical role of religious traditions in management education. Journal of Business Ethics, 38(1-2), 91-96.

Graafland, J., Kaptein, M., \& Schouten, C. M. D. (2006). Business dilemmas and religious belief: An explorative study among Dutch executives. Journal of Business Ethics, 66(1), 53-70.

Haniffa, R., \& Hudaib, M. (2007). Locating audit expectations gap within a cultural context: The case of Saudi Arabia. Journal of International Accounting, Auditing \& Taxation, 16(2), 179-206.

Ho, Y. H. (2009). Associations between the religious beliefs and ethical-reasoning abilities of future accounting professionals. Social Behavior and Personality, 37(5), 673-678.

Hunt, S. D., \& Vitell, S. (1993). The general theory of marketing ethics: A retrospective and revision. In N. C. Smith, \& J. A. Quelch (Eds.), Ethics in marketing (pp. 775-784). Homewood, I.L.: Irwin Inc..

IFAC. (2012a). IFAC policy position paper \#4. Retrieved December 15, 2012, from $\mathrm{http}$ //www.ifac.org/publications-resources/iaesb-response-ifac-policy-position-paper-4-public-interest-framework-account

IFAC. (2012b). Responses to the member body compliance program. Retrieved November 10, 2012, from http://www.ifac.org/about-ifac/membership/compliance-program/compliance-responses

IFAC. (2013). Code of ethics for professional accountants. Retrieved June 15, 2013, from http://www.ifac.org/sites/default/files/publications/files/2013-IESBA-Handbook.pdf

Keller, A. C., Smith, K. T., \& Smith, M. S. (2007). Do gender, educational level, religiosity, and work experience affect the ethical decision-making of U.S. accountants? Critical Perspectives on Accounting, 18, 229-314.

Kim, D., Fisher, D., \& McClaman, D. (2009). Modernism, christianity, and business ethics: A worldview perspective. Journal of Business Ethics, 90(1), 115-121.

Lewis, M. K. (2001). Islam and accounting. Accounting Forum, 25(2), 104-127.

Loft, A., Humphrey, C., \& Turley, S. (2006). In pursuit of global regulation: Changing governance and accountability structures at the International Federation of Accountants (IFAC). Accounting, Auditing \& Accountability Journal, 19(3), 428-451.

McMahon, T. F. (1986). Creed, cult, code and business ethics. Journal of Business Ethics, 5(6). 453-463.

Rest, J. R. (1986). Moral development: Advances in research and theory. New York: Preager.

Sheldahl, T. K. (1980). Towards a code of professional ethics for management accountants. Management Accounting, 62(8), 36-40.

Worldmapper. (2012). SASI, University of Sheffield. Retrieved December 1, 2012, from http://www.sheffield.ac.uk/sasi 